\title{
How to share what we used to own
}

\author{
Dr Artur Grisanti Mausbach \\ Contact: artur.mausbach@rca.ac.uk \\ Daniel Quinlan \\ Contact: dan.quinlan@rca.ac.uk \\ Samuel Johnson \\ Contact: sam.johnson@rca.ac.uk \\ Intelligent Mobility Design Centre \\ Royal College of Art \\ 4 Hester Road, London SW11 4AY, UK
}

\author{
Dr Luke Harmer \\ Contact: 1.a.harmer@lboro.ac.uk \\ Loughborough Design School, \\ Loughborough University, \\ Loughborough, United Kingdom.
}

\begin{abstract}
This paper looks at the challenges to shift the mobility culture from ownership to sharing, in the context of ecological and autonomous vehicles. It proposes the observation of social aspects of car use and to build knowledge to educate people to live in a shared mobility scenario, and points out the importance of developing meaningful mobility experiences
\end{abstract}

The paper looks into the context of rural transport and questions the monetization of shared mobility through the analysis of the Joyful Journeys project which observes the case of an elderly driver who gives lifts in a countryside village.

It addition, it investigates through a new analysis of the RCA's Frisbee car sharing project, aspects of placemaking and identity related to sharing cars. It concludes by indicating how the concepts of resilience, inclusive design and identity can develop in a shared mobility context. The paper proposes the development of sharing cars beyond business models, product and services development, but through designing a cultural change.

Keywords: design, car sharing, journey, autonomous cars, placemaking, mobility

\section{INTRODUCTION}

The automotive industry is facing its most revolutionary moment since it established its models of production, business and aesthetic paradigms in the first half of the Twentieth Century. This paper explores the challenge to tackle the environmental and health threats caused by unsustainable mobility models through the sharing of mobility. These threats have initiated a non-reversible process of change in the development of technologies, products, services and habits related to the ways we travel. This paper discusses the rapid changes in mobility before exploring contemporary models of shared ownership. It follows with an analysis of how mobility sharing might become more joyful, through a project developed jointly by the Royal College of Art and Loughborough University which observed journeys in the countryside and a discussion of how inclusivity and placemaking could enrich our journeys. In addition, it analyses the outcomes of the Frisbee project (Mausbach, 2010) through the perspective of current business models and the creation of resilient solutions to share mobility addressing needs and aspirations of place and people.

The automobile was set as both utilitarian and symbolic object from its inception. Whilst becoming the materialization of modern man's desires and aspirations (Montemaggi, 2008), the car has changed cities, reshaped culture and developed its own mythical context. The cultural influence of the car became subject of academic studies through Roland Barthes Mythologies (1957) which indicates that cars were 
symbols of collective aspirations, that cars were the new 'cathedrals'. Tom Wolfe essay The Kandy-Kolored Tangerine-Flake Streamline Baby (1966) about custom cars also confirmed the point that cars meant more for the American kids 'than architecture did in Europe's great formal century, 1750 to 1850 ' (Wolfe, 1966). Wolfe points out that cars were representation of freedom, sex, style, color, motion and power. Owning a car was a symbol of empowerment and an important milestone in life. Exposing the downside of car culture, Jane Jacobs wrote in The Death and Life of Great American Cities (1961) that 'the purpose of life is to produce and consume automobiles'.

The development of cars from functional object to myths and status symbols, is related also to how they would be consumed as products, and how mobility would become inseparable from aspirational social behavior.

In the beginning of the twentieth century, the Ford Model-T and Ford's production line initiated a revolution in mobility as a function, which evolved to unprecedented cultural and marketing scales. 'To Ford the car was an absolute democratic necessity, a utilitarian tool, an impression of man's ingenuity and his freedom. To Alfred Sloan, from General Motors, the same car represented an opportunity to seduce the consumer with ideas of social competition and cultural modelling' (Bayley, 2008). Sloan created the model-year at GM, and with this an inevitable product obsolesce. The car transformed from practical tool to fashionable object. The evolution of this model added to the idea of the citizen subordinated to consumer explored by Zygmunt Bauman (Eco, 2016). Stuart Walker points out that the traditional models of consumption and the character of products defines unsustainable practices. 'The fundamental character of many contemporary products - embodied in their aesthetics, their relatively low cost and their rapid disposal and replacement - is inextricably wedded to inadequate consumerism, energy use, waste and pollution' (Walker, 2011).

To change to a more sustainable mobility paradigm, it is necessary not only to focus on development of new technologies, new products and services, it is necessary to change the mindset about our consumption models and ownership. Manzini and Vezzoli (1998) classified four levels of interference to reach sustainable solution: 1) The ecological redesign of existing products and services: considering the life-cycle of the product; improving global efficiency in terms of energy and resources consumption; enhancing recycling and reuse of materials and components. 2) The creation of new products and services to replace current ones: designing more ecological new products and services; working with this focus, more innovative technologies can be applied than by redesigning products. 3) The creation of a new and sustainable mix of products and services: offering a different and more sustainable way to achieve the benefits a product can give, through a new mix of products and services - must be committed to cultural change and new consumer behavior. 4) The proposal of new scenarios corresponding to more sustainable ways of living: developing at a cultural level; promoting new standards of quality; changing the structure in response to demand.

More essentially, Manzini (1997) added that what the 'user demands are not products or services' - the car or the sharing system, but the 'results that these products and services permit them to achieve' - the social and personal benefits of mobility. Therefore, it is important to investigate the possibilities of sharing beyond traditional product and service development, and in the direction of a new social culture to mobility.

\section{OWNING AND SHARING MOBILITY}

The concept of shared mobility has grown strong, especially, as a possible solution to diminish the impacts of the automobile in the cities. It has grown even stronger as a business opportunity to service and software-based enterprises in the Mobility as a Service (MaaS) sector (ITS, 2018). According to a study by McKinsey \& Company, in 2016 the growing sharedmobility market represented nearly $\$ 54$ billion just in China, Europe, and the United States (Grosse-Ophoff, Hausler, Heineke, Moller, 2017).

Although the automotive OEMs have frequently touched on the subject proposing shared models of their current selling (e.g. Smart app) or to enter the MaaS market (e.g. Ford Chariot), there is a resistance to keep the traditional business model as they have stood for the last hundred years. These types of initiatives are not the priority of publicity campaigns or motor shows, which are mainly dedicated to private cars. Shared vehicles, like the Renault EZ-GO (Renault, 2019) make appearances as future concepts, often to become reality together with autonomous vehicles technology, in an uncertain date. The aesthetic of the products also points out the expectation about when the product will become reality (figure 1). 


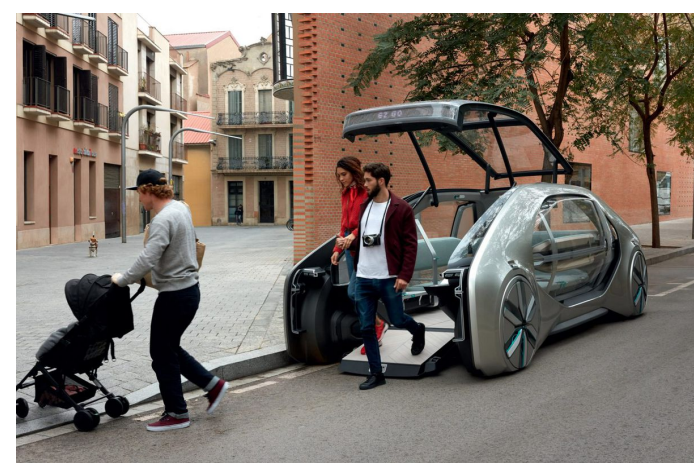

Figure 1: The shared autonomous concept car Renault EZ-GO, presented in 2018.

Vehicle ownership models are undergoing significant change with the growth of vehicle financing. In 2017, the leasing and rental industry accounted for more than one in every seven vehicles on the UK's roads, and cars represented $88 \%$ of the purchase of new vehicles for leasing and rental (Oxford Economics, 2018). Leasing models can be considered a hidden or softer transition to not owning a car but paying for using it over a long period. It is also represents a significant business sector of the mobility market. Oxford Economics reports explains that 'the opportunity to lease and rent vehicles offers firms and households access to modern, fuelefficient vehicles without the strain of upfront capital expenditure'(Oxford Economics, 2018). Consumers apparently have become comfortable with not owning a vehicle and it appears possible that they might also benefit from the environmental, and social benefits of sharing.

Shared mobility, however, has not developed to its full potential. Currently it accounts for only $1 \%$ of the $30 \%$ of annual miles travelled it could potentially achieve (Grosse-Ophoff, Hausler, Heineke, Moller, 2017). The high costs of using shared services frequently and the lack of availability in rural areas are recognized limitations. Sharing systems are rarely viable in cities with fewer than half a million inhabitants. Thus, there is an opportunity to develop alternative systems of shared mobility, that would support the needs of the rural areas.

Comparing the demographics of the population of UK cities with rural locations, helps to understand the different requirements of both mobility contexts.

Considering the examples of London and Devon (figure 2 ), indicates the need to understand and research further the relationship between age groups and place to propose mobility solutions which would tackle car ownership. Age group preferences are also likely to have an affect as to wether they are willing to share their vehicle or to adopt autonomous technology.
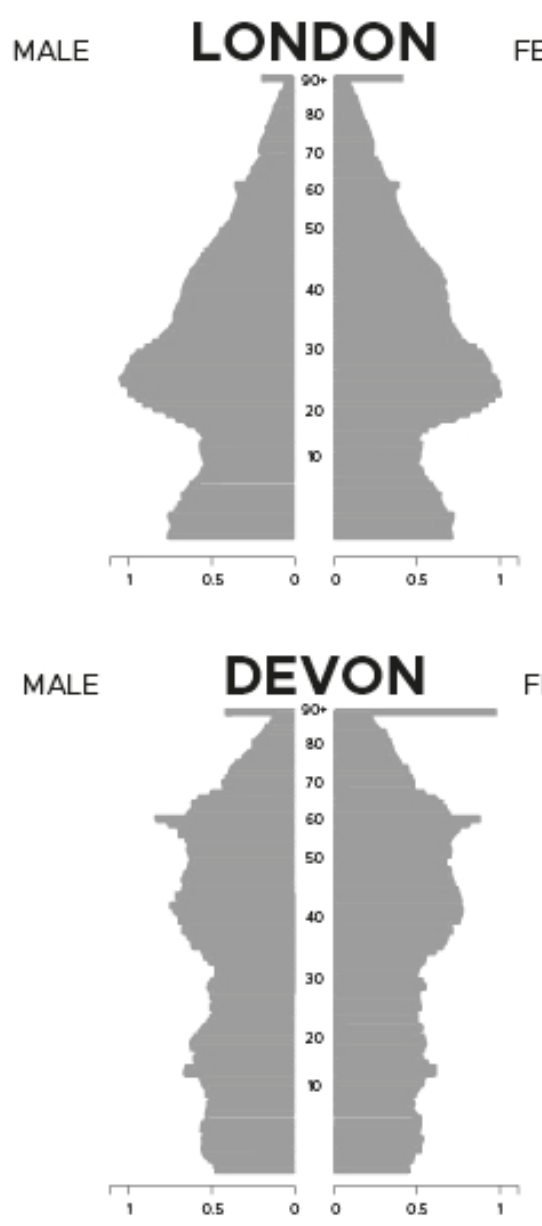

Figure 2. Population of London and Devon (Office for National Statistics, 2019):

While for the earlier generations driving might still be considered a valuable experience, for millennials, as Wolmar (2018) points out, there is a stronger trend of not driving and not owning a car. In the USA, the percentage of new driver license holders has dropped from $76 \%$ in 2000 to $71 \%$ in $2013 \%$ (Sivak, 2013). This trend is not necessarily driven by predicting the advent of the autonomous vehicle. According to Vierecki, (2016) in the Western markets, the trend is aligned to migration to urban areas, where cars are not essential, and public transport can easily fulfill their needs. In this context MaaS like Uber provides a more exclusive service, where the ecological footprint of the journey increases compared to that of using public transport. The process can lead to a stratified mobility model, defined by classes of travelling regulated by the acquisition power of the user, which is more similar to the private ownership - or airline model - than public transport. 


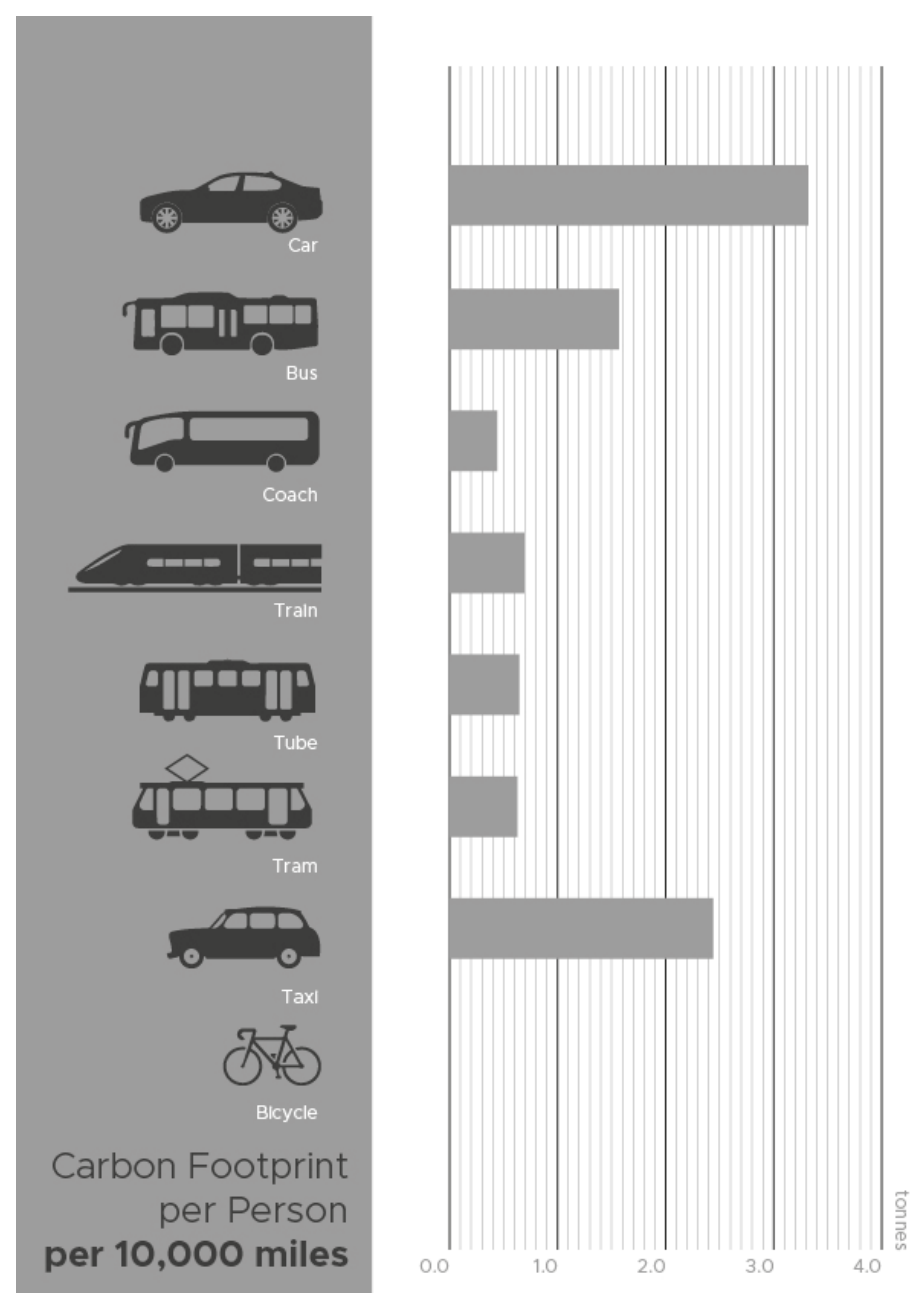

Figure 3. Ecological Footprint of your personal mobility choice (Carbon Calculator, 2019).

Nevertheless, the development of autonomous vehicles has taken the spotlight as a technology development that could potentially increase the benefits of car sharing. The McKinsey \& Company (2016) report indicates that the annual growth of the shared mobility market could almost double ( $15 \%$ to $28 \%$ ) with the adoption of self-driving taxis - also called robo-taxis. Autonomous cars would eliminate the cost of the driver, which currently accounts for $45 \%$ of the service (GrosseOphoff, Hausler, Heineke, Moller, 2017).

Autonomous vehicles will depend not only on the developments of $5 \mathrm{G}$ and IT but legislation, insurance rules and even city planning. Whilst urgent changes are needed to make mobility more sustainable, the implementation of fully autonomous vehicles may create a 'moving targeting' potentially postponing changes on business and usage models while urgent changes are needed to reach more sustainable solutions.
In this research, the current models of sharing are organized in two main groups: monetized and nonmonetized. The monetized group includes Rental Cars, Car-Sharing, Ride Hailing, Carpooling and Car Clubs. Non-monetized are lifts and hitchhiking.

Ride hailing services are the ones enabled by on-line and app-based platforms to connect passengers and drivers, which generally use their own vehicles. (Wikivoyage, 2019). Uber is an example of this kind of services. Ride hailing offered an alternative to taxis and minicabs, but at the same time it takes passengers from buses and the other transport systems. It has grown significantly as an alternative to owning a vehicle.

Car-sharing is usually considered as a system where you can access cars for self-driven journeys. Zip Car is a typical example of this kind. Car-sharing is also referred to as Car Clubs, however, examining the characteristics of these services, and development of the market, it is possible to differentiate them. Car Clubs are a better definition of services where the periodical fee is significant to the membership. At the same time, the focus of the car clubs is not only about mobility, but also to provide status and leisure to the members. The Porsche Passport subscription is a good example. It allows the member to access and use different vehicles from the Porsche model range on different days of the week: a sportscar on Friday and a SUV on Monday. The subscription has the monthly cost of 2000 to 3000 US Dollars (Porsche USA, 2019). The premium paid to be part of the club is beyond the expected cost for personal mobility. Traditional Rental Cars operate by Avis, Hertz, Europecar and others also offer so-called premium vehicles on daily rates, to satisfy the aspiration for fun and status.

Quite opposite in terms of costs, Carpooling is sharing journeys between more than one person in an app-based sharing car. On one side, shared mobility and vehicle pooling can create uncomfortable dynamics among passengers who are likely to be strangers (GrosseOphoff, Hausler, Heineke, Moller, 2017), younger generations, however, see it as an opportunity to meet new people. Apps like BlaBlaCar provide carpooling services where a person can share their journey, in a contemporary version of hitchhiking: digital and profitable. These apps also provide a safer environment to social encounters, through car sharing, which Hitchhiking (also known as thumbing or hitching) originally lacked. Hitchhiking, on the other hand, was often a free ride. 
Giving Lifts, which can be differentiated from hitchhiking, because it has been previously organized by the driver and passengers, promotes a safer and interesting way of socializing. It is usually organized inside a context: school, work, party, neighborhood, etc. And it can also become a regular activity. This category of car sharing was studied in the Joyful Journeys project (Mausbach, Harmer, Johnson, Quinlan, Kille-Speckter, 2018), addressed in the following section.

\section{MAKING RURAL VEHICLE SHARING JOYFUL}

Observing the current contexts of car use, it is possible to identify different ways to reach similar ecological benefits to those of sharing vehicles. The Royal College of Art - Intelligent Mobility Design Centre developed the Joyful Journeys project with the Loughborough School of Design, to investigate how meaningful mobility experiences are created. The project applied journey shadowing, interviews, design provocation and public outreach responses to identify cultural values inside the current context of mobility. As a result of the investigations a 'joyful journey' was defined as not only a journey that is enjoyable, bringing pleasure or happiness, but one that is imbued with meaning (Harmer, Cain, Mausbach, 2019). These are journeys that might be described as joyful in spite of the difficulty or hardship faced in completing them. One of the journey shadowing subjects was an older woman who gives people lifts in a rural location in the UK.

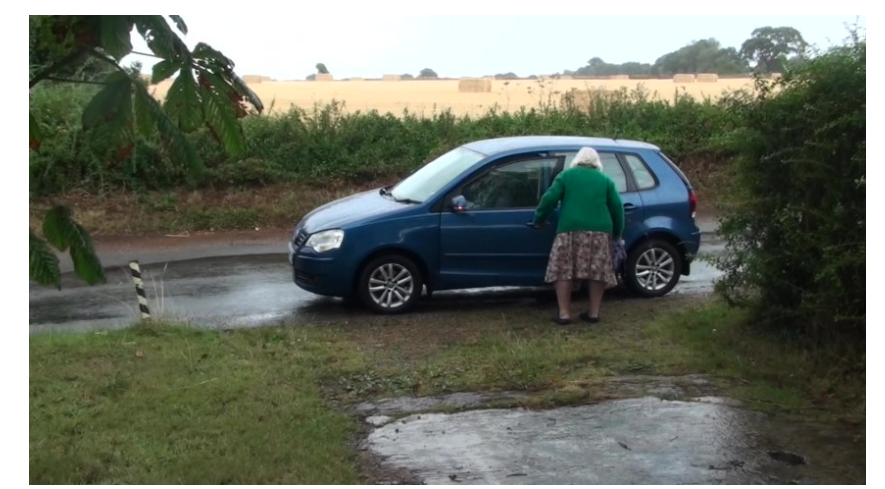

Figure 4: Giving a lift - Journey Shadowing and interview 1

Musselwhite (2018) reports that for older people, driving can be a critical part of maintaining wellbeing, satisfying utility, psychosocial and aesthetic needs. Comparing the actions of the lift provider onto the six factors presented by Hassenzahl et al., for promoting wellbeing (2013) suggests that providing lifts can create not only the social benefits necessary for subjective wellbeing but also the competence and stimulation as the car driver. The Journey Shadowing undertaken in interview 1 (figure 4) showed the importance of giving lifts, as well as driving for the well-being of the participant. Illustrating how the habits of giving lifts configured a non-monetized shared mobility solution which also helped to build the social.

Understanding the joyful aspects of journeys helps to create a framework to the question of how we might share what we used to own. The project focused on the countryside and older age groups which are arguably less likely to adopt new types of mobility. The analysis also explored links to local bus services and placemaking, to understand how the vehicle can become an extension of public spaces and serve communities beyond commuting needs.

In the perspective of a growth in the market of mobility as a service (Grosse-Ophoff, Hausler, Heineke, Moller, 2017), the Joyful Journey project pointed out the possibility of developing and reclaiming behaviours and mobility habits which can benefit wider health and social goals. At the same time, it indicates that it is important to analyse psychological consequences of the migration to autonomous vehicles. Looking into how autonomous shared cars will impact the habits, behaviours and psychological well-being will be necessary to create an inclusive, resilient and sustainable mobility model.

To develop an inclusive solution for mobility is important to address the needs of all populations, both in the city and countryside. This latter group represents a challenge to create a viable economic solution, but also is an opportunity to develop new services, vehicles and habits.

In the UK bus patronage is in decline with rural bus services increasingly threatened (CB Transport, 2018). Autonomy could create the potential to control our journeys more and to enable choreography of the elements that make up an experience. Rural communities need effective transport to thrive and in particular older people are most reliant on these services for practical and social purposes. The infrastructure complexity of rural transport and the demise of the rural bus creates a unique opportunity to conceive and trial better shared transport. 
The combination of future vehicle possibilities and shared mobility could have perhaps the most profound impact on rural transport. Virtual connectivity, vehicle electrification and autonomy could provide ideal solutions to complex economical and logistical problems.



Figure 5. Gateway Project Isolation pod RCA (2016)

However, a future of individualized, driverless pods could increase isolation and loneliness, as discussed in the RCA Gateway project (2016). Thus, making a local bus service and the lift giving car driver redundant and removing an important social aspect of rural community. The 'Joyful Journey' project demonstrated that valued journeys are facilitated by the vehicle, not dictated by it, creating a connection between people and their environment. However, thoughtfully considered vehicle autonomy could increase social inclusion through understanding how vehicle sharing acts as a social agent. For example, many users prefer someone on board for safety, assistance and companionship (Center for Global Policy Solutions, 2017; Comfort, 2018) and autonomy could provide new opportunities for others to assist those who are less able to travel.

Rural households spend more than urban households on transport: $19.5 \%$ of disposable income per week at 2017 prices, compared with $15.7 \%$ for urban households (Office for National Statistics, 2018). Autonomy could not only provide more cost-effective solutions (Institute of Mechanical Engineers and Age UK, 2017) but also create independence for those who can no longer drive (Ormerod et al., 2015). The potential of mobility connectivity is already being seen, the precursors having been trialed in rural communities: through sharing modes of transport, rural car clubs and community-based transport services and on-demand systems (Stockley, 2016).
Vehicle autonomy and continued vehicle electrification are increasingly likely within the medium term (Crown,2019). Before the technical possibilities of the next generation of rural transport occur, it will be necessary to conceptualize, design and trial with users the resulting experience of the system, vehicle and interface through prototyping, creating a vision of the next generation of rural transport.

\section{PLACEMAKING AND IDENTITY}

According to the architect Richard Rogers, 'cities are the places where people meet to exchange ideas, trade, or simply relax and enjoy themselves. A city's public domain - it's streets, squares, and parks - is the stage and the catalyst for these activities' (Gehl, 2010). The idea of placemaking crystalized from the reaction against concepts of city promoted by the Modern Architectural movement.

In 1961, Jane Jacobs' wrote 'The Death and Life of Great American Cities' (Jacobs, 1961). She criticized the 'garden city's paternalistic tedium, Le Corbusier's correct, magnificent and egocentric game, and the dehumanization of cities fragmented and divided into isolated areas' by the oppressive presence of the automobile. Jane Jacobs suggested that high population densities, mixed land use, street interaction and people with different activities and time schedules all added to the enrichment of the city life (Mausbach,2010). 'She pointed out how the dramatic increase of in car traffic and the urban planning ideology of modernism that separates the uses of the city (...) would put an end to urban space and city life and result in lifeless cities devoid of people (Gehl, 2010).Fifty years later, in 'Cities for People' (2010), Gehl still advocates for a lively, safe, healthy and sustainable city, regarding the private cars as the biggest barrier for creating a better city.

According to Deyan Sudjic (2016), 'cities are formed as much as ideas as they are by things. The car, which is clearly a thing rather that an idea, was meant to offer personal mobility rather than lead to the emergence of out-of-town shopping, toxic air pollution and traffic jams'. Concepts of smart mobility appear to be more aligned to the principles of fostering community life in cities, through design and policies that encourage the humanized interaction and respect for place and culture. An active and healthy public realm is key to placemaking and mobility has the potential to expand the benefits if designed to meet not only the function of commuting but also social aspirations. 
Until now, public transport has been an extension of public urban spaces in mobility. Infrastructure, from streets to avenues, bus stops trains stations and airports, play a role on defining the character of the place and therefore, have the potential for placemaking. Vehicles are unlikely to contribute to placemaking where they lack or limit social interactions. Rare examples where they have contributed are the historic trams of San Francisco and Lisbon, or the London double-decker bus. Biking and walking are the favorite mobility solution proposed by architects and planners to bring back life to the streets. However, it is recognized that whilst cars can bring life an urban area, private cars are seen a problem and removing them from streets is a common theme to placemaking proposals.

One of the arguments of MaaS services is that it has the potential to reduce the space taken by the car in the urban environment. For it to be effective, it will be necessary to reduce the presence of private owned vehicles on the streets. Significantly that means replacing resident parking permits for corporate parking permits, operated by the MaaS companies, and reducing the overall number of parking spaces, posing the question of who should manage sharing car of public interest. It is important to acknowledge the potential consequences of adopting MaaS into the public realm if there is a focus on placemaking.

As car sharing systems are becoming more popular, differentiation in service provision is beginning to become apparent. Companies like ZIP Car which operates in London with electric and ICE vehicles use regular automobiles from traditional OEMs like VW and Ford. Bluecity uses the bespoke Pinninfarina designed Bollore electric car. The two companies also represent different approaches to aesthetic impacts on the landscape. The Bollore Bluecar car makes a stronger statement about the presence of the sharing vehicle in the city, as a homogenous typology. The VW Golfs, E-Golfs and Polos of ZIP Car are more likely to mingle with the rest of the cars on the street. Interestingly, one of UBER's attributes is not being recognize as a Taxi in the streets. Uber could easily, as a rental car, have the temporary status of an owned vehicle.

While cities particularities will define the business models, they will also define the design of the vehicles, services and experiences. McKinsey's (2016) report on shared mobility points out that industry has identified that a one-size-fits-all mobility model won't be favored, and that market segmentation will happen at city level.
'The transformative path could see rapid acceleration with the introduction of autonomous vehicles and supportive city initiatives, enabling companies to offer new options for user experience and monetization based on purposed-built vehicles'. (Grosse-Ophoff, Hausler, Heineke, Moller, 2017).

Vehicle Design research at the RCA has investigated the question of identity of people and places in mobility designs and questioned if we are prepared to give up our tastes and preferences when it comes to choices of personal mobility. The Frisbee project (Mausbach, 2010) showed that shared mobility aligned with smart customization can create an intense connection between user and vehicles and places.

The project brief asked a group of 7 designers from the Royal College of Art master course to conduct research into car users and their environment in a specific London location, using non-participant observation, to develop a sharing car for the specific context. The design responses were open to the designers to create; with the choice to customize for an individual user, or to a neighborhood, city, brand or country level. The briefing specified that: 'A blank screen of a car, the Frisbee is the ultimate concept for a car-sharing vehicle which morphs into a form dedicated to the individual user when they connect to it and can be kept as their digital car in a virtual form.' (Mausbach, 2010).

The design responses produced were more focused on expressing the character of the neighborhood than individual users or brands. Two of the designs, (figures 6 and 7) however, created ways for a person to add their contribution to the 'story' of their shared vehicles, representing the need of the user to deliver a message through its temporary ownership, even if it was a subtle message. Another design proposal (figure 8) explored the idea of converting the vehicle into urban furniture while it was not on the move. Thus, the shared vehicle would integrate the public realm and be a new hub for people to meet and so on, create a city - as Richard Rogers suggested.

The Frisbee project pointed out a focus on place as a brief to develop designs for shared mobility, which also has been highlighted in the McKinsey report. The area for personal customization will possibly be the digital components of the services and products. This would follow the current trends of product development linked to internet and screen-based semiotics. 




Figure 6: Presentation board for BedZED Frisbee by David Eburah (Mausbach, 2010). David's design explores the use of an artificiallygrown spider silk that collects information from the road and the environment, as the wheels rotate, creating a particular story for each journey and each user.

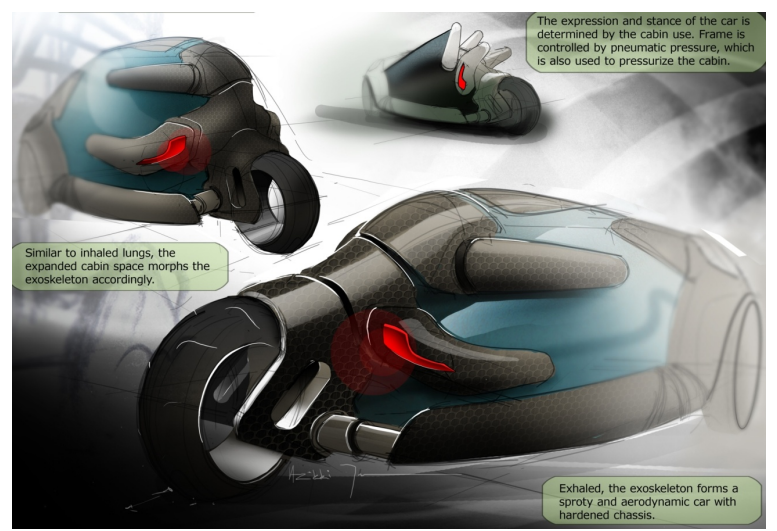

Figure 7: Presentation board of BedZED Frisbee by Heikky Juvonen (Mausbach, 2010). Heikky Juvonen's design for the Frisbee is based on a 'skeleton and skin' architecture. The user can choose different expressions and determine the dimensions of the vehicle through the variation on the air pressure in the skin layer and the movement of the skeleton of the vehicle.

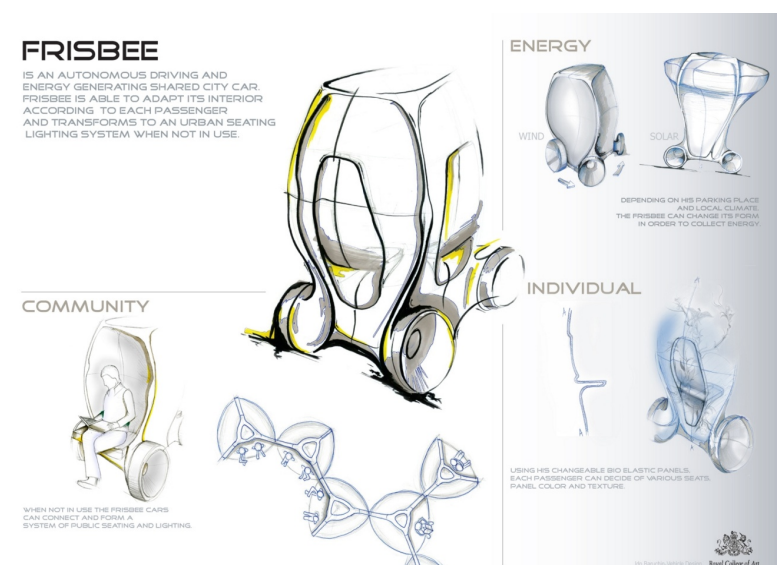

Figure 8: Presentation board of Hoxton Frisbee by Ido Baruchin (Mausbach, 2010). In addition to the Frisbee concept, his vehicle transforms itself into street furniture when parked in the Hoxton Square area. According to Ido (2009) the sense of community of
Hoxton's users will extend the sharing system from public spaces to the journeys.

\section{CONCLUSIONS AND FUTURE RESEARCH}

There are new opportunities emerging to design and develop new mobilitys focused on sharing systems. These design solutions will promote more sustainable mobility whilst relating to local needs and aspirations reflecting personal choices and enabling digital customization.

Homogeneous designs of shared cars - 'one size fits all' - may not only be a problem for public acceptance but may also pose complexities in their development into a resilient and inclusive solution. In the one side, homogeneity, monetization and branding of MaaS enterprises are a model of a top-bottom shared mobility, where the user is a likely to be a consumer.

The observation of vernacular experiences of shared journeys shows that there is potential to develop bottomtop solutions for share mobility which will respond to the needs and aspirations of different age groups and contexts. The research made in the context of the UK countryside pointed out the difficulties in implementing sharing systems in a low density and low populated area, which is nevertheless in need of new mobility solutions that could replace current bus services.

Research is necessary to define possible models for future rural transport. When mobility provided as a service and it is not financially viable, it is necessary to change the mobility on a cultural and educational level to achieve sustainable solutions. This highlights how mobility is much more than about commuting but also a social space. Through the Joyful Journeys project, an initial observation of rural locations and local habits illustrated how these much more nuanced ideas of mobility could work.

Digital interaction can also help to organize nonmonetized mobility systems. According to Caio Vassão (2017) the context of future cities and smart city communities will have a more determinant role in city planning, whilst developing a new social interaction repertoire, partially derived from the boom of digital interaction. There is an expectation that bottom-up, lowscale infrastructure and mobility solutions might respond more efficiently to local needs which can be projected to a change in the culture of how to share mobility. 
The understanding of a shared-vehicle as an extension of a public space is key to improving the impacts of new mobility and avoid some of the pitfalls of the introduction of the automobile. The Joyful Journey project showed the importance of people interaction during journeys and showed that shared vehicles have the potential to become a social space. Manzini and Vezzoli (1998) proposed that the more effective way of reaching sustainable solutions is by creating new scenarios which are related to more sustainable lifestyles. A new culture of mobility is, therefore, necessary, achieved through exploring the relationships between places, people and mobility that create social value.

We need to question why and how we will share meaningful mobility experiences. We must educate ourselves to create habits of sharing that develop a mobility model for citizens above consumers. These challenges exist beyond technology and the design of products and services. Creating a culture of sharing involves the whole ecosystem to meet its functional and symbolic needs.

Mobility is not only about business and building things, it is about how to design 'ideas'. If the car was a 'thing', as suggested by Sudjic (2016), sharing mobility is an 'idea'.

\section{REFERENCES}

BARTHES, Roland. (1957) Mythologies. London: Vintage. BAYLEY, Stephen. (2008) Cars Freedom Style Sex Power Motion Colour Everything. London: Conran Octopus.

CARBON FOOTPRINT LTD. (2019) Carbon Calculator

https://www.carbonfootprint.com/calculator.aspx accessed in February 2019. Secker.

ECO, Umberto. (2016) Chronicles of a Liquid Society. New York: Harvill

Crown (2019) Future Mobility; A time of unprecedented change in the transport system. Government Office for Science. Retrieved from https://assets.publishing.service.gov.uk/government/uploads/system/uploads/a ttachment data/file/778495/future of mobility final.pdf

HARMER L., CAIN R., and MAUSBACH, A. (to be published in 2019), 'Joyful Journeys': putting wellbeing at the centre of future travel. In CAIN R., Design For Well-Being. Routledge. HARROW, D. GHEERAWO, R. et al. (2018) Gateway project report. London: Royal College of Art. HASSENZAHL, M., ECKOLDT, K., DIEFENBACH, S., LASCHKE,

M., LEN, E., KIM, J., (2013). Designing moments of meaning and pleasure. Experience design and happiness. International Journal of Design 7. Institute of Mechanical Engineers and Age UK. (2017). The Future of Demand Responsive Transport. Retrieved from www.ctauk.org/

UserFiles/Documents/The-Future-of-Demand-Responsive-Transport. Pdf GEHL, J. (2010). Cities for People. London: Island Press. GROSSE-OPHOFF, A. HAUSLER, A. HEINEKE, K. MOLLER, T. (2017) How shared mobility will change the automotive industry. McKinsey \& Company: April 2017. https://www.mckinsey.com/industries/automotive- and-assembly/our-insights/how-shared-mobility-will-change-the-automotiveindustry

ITS. MaaS Market: Concept to delivery. ITS International: 8

Novemember 2018, https://www.maas-market.com/events/london-uk-2019

JACOBS, Jane. (1961) The death and life of great American cities. New

York: Random House.

MANZINI, Ezio. (1997) Leapfrog strategies- toward new services combinations. Chapter in: van HINTE, Ed. Eternally Yours - Visions on Product Endurance. Rotterdam: 010 Publishers.

MANZINI, Ezio and VEZZOLI, Carlo. (1998) Lo sviluppo di prodotti sostenibili. Rimini: Maggioli Editore.

MAUSBACH, Artur G. (2010) Paradigm Shift: the aesthetic of the automobile in the age of sustainability. Thesis ( $\mathrm{PhD})$, Royal College of Art. London: CAPES and RCA.

MAUSBACH, HARMER, JOHNSON, QUINLAN, KILLE-SPECKTER (2018) Joyful Journeys. Project developed at the Intelligent Mobility Design Centre. London: Royal College of Art https://www.rca.ac.uk/researchinnovation/intelligent-mobility-design-centre/choreography-mobility/ Accessed in February 2019.

MONTEMAGGI, Marco. (2008) 'Una lunga cavalcata: i tempi 'Eroici' dei motori in Italia'. Chapter in: MATERA, Eugenio and PIETROGRANDE, Patrizia. (eds.) Il Mito della Velocitá. Arte, motori e societá nell'Italia del ' 900. Florence: Giunti.

MUSSELWHITE, C., 2018. Mobility in Later Life and Wellbeing, in: Quality of Life and Daily Travel. Springer, pp. 235-251.

Ormerod, M., Newton, R., Phillips, J., Musselwhite, C., McGee, S. and Russell, R. (2015). How Can Transport Provision and Associated Built Environment Infrastructure Be Enhanced and Developed to Support the Mobility Needs of Individuals as They Age? Retrieved from www. gov.uk/government/uploads/system/uploads/attachment_data/ file/443508/gs15-7-future-ageing-transport-er23.pdf

OFFICE FOR NATIONAL STATISTICS, (2019):

https://www.ons.gov.uk/ Accessed in February 2019.

OXFORD ECONOMICS (2018). The economic impact of the motor vehicle leasing and rental. Report. https://bvrla-

sslstaging5.pix18.london/uploads/assets/uploaded/107f8a52-807d-4a0095e8a67885c8a834.pdf Accessed in February 2019.

Office for National Statistics. (2018). Estimates of the population for the UK, England and Wales, Scotland and Northern Ireland. Retrieved from www.ons.gov.uk/peoplepopulationandcommunity/ populationandmigration/populationestimates/datasets/population estimatesforukenglandandwalesscotlandandnorthernireland PORSCHE USA (2019) Porsche Passport .

https://www.porschepassport.com/membership Accessed in February 2019. RENAULT (2019). Mobility on demand for everyone.

https://life.renault.co.uk/concept-cars/ez-go-concept/ Accessed in February 2019.

SIVAK, M. (2013) 'Has Motorization in the US peaked?', University of Michigan, Transportation Research Institute, June 2013.

SUDJIC. D. (2016) The language of the city . St Ives: Penguin Publishers.

VASSÃO, C. A. (2017) Design and Politics: Metadesign for social change Strategic. Design Research Journal, 10(2): 144-155 May-August 2017. Unisinos - doi: 10.4013/sdrj.2017.102.07.

VIERECKI, R. et al. (2016). Connected car report 2016: opportunities, risk and tturmoil on the road to autonomous vehicles. Strategy\&, 28 September (https://pwc.to/2wUs3IT).

WALKER, Stuart. (1997) 'Conscientious Objects - Product Aesthetics in the Context of Sustainability'. Chapter in: van HINTE, Ed. Eternally Yours Visions on Product Endurance. Rotterdam: 010 Publishers.

WALKER, Stuart. (2011) The Spirit of Design: Objects, environment and meaning. New York: Earthscan.

WIKIPEDIA (2019) Hitchhiking

https://en.wikipedia.org/wiki/Hitchhiking accessed in February 2019.

WIKIVOYAGE (2019) Ride Hailing

https://en.wikivoyage.org/wiki/Ride_hailing_services accessed in February 2019.

WOLFE, Tom. (1966) The kandy-kolored tangenrine-flake streamline baby. London: Jonathan Cape.

WOLMAR, C. (2018). Driverless cars: on a road to nowhere. London: London Publishing Partnership. 